\title{
Patient-reported outcomes in transition from high-dose U-100 insulin to human regular U-500 insulin in severely insulin- resistant patients with type 2 diabetes: analysis of a randomized clinical trial
}

\author{
Samaneh Kabul ${ }^{1 *}$, Robert C. Hood ${ }^{2}$, Ran Duan ${ }^{1}$, Amy M. DeLozier ${ }^{1}$ and Julie Settles ${ }^{1}$
}

\begin{abstract}
Background: Initiation and titration of human regular U-500 insulin (U-500R) with a dosing algorithm of either thrice daily (TID) or twice daily (BID) improved glycemic control with fewer injections in patients with type 2 diabetes treated with high-dose, high-volume U-100 insulin. The objective of this analysis was to compare patient-reported outcomes between U-500R TID and BID treatment groups in this titration-to-target randomized, clinical trial.

Methods: In this 24-week, open-label, parallel trial, 325 patients were randomized to TID $(n=162)$ or BID $(n=163)$ U-500R after a 4-week lead-in period (screening). The Treatment Related Impact Measure-Diabetes (TRIM-D) and EQ-5D-5L questionnaires were administered at screening, baseline/randomization, and endpoint (24 weeks). The Visual Analog Scale-Injection Site Pain (VAS-ISP) was assessed at baseline/randomization, 12 weeks, and endpoint.

Results: The TRIM-D showed statistically significant improvements in overall scores from baseline to endpoint for both BID and TID groups, most domains in the TID group, and all domains in the BID group. The BID group achieved better scores than the TID patients in overall and in treatment burden, daily life, and compliance domains $(p<.05)$. EQ-5D-5L index scores showed no statistically significant differences for TID and BID groups (and no differences between TID and BID groups) from baseline to endpoint. VAS-ISP scores improved for both treatment groups $(-5.60$ TID; $-6.47 \mathrm{BID} ; p<.05$ for both) from baseline to endpoint.
\end{abstract}

Conclusions: U500 can be successfully titrated for improved glycemic control using BID and TID regimens with diabetes-specific Patient-Reported Outcomes showing improvements in both arms; however, BID had better scores than TID in overall, treatment burden, daily life, and compliance domains.

Trial registration: These secondary analyses are based on the study first received January 22, 2013 and reported in Clinical Trial Registry No.: NCT01774968.

Keywords: Severe insulin resistance, Type 2 diabetes mellitus, U-500R, Patient compliance, High-dose insulin therapy, Patient-reported outcomes

\footnotetext{
* Correspondence: kabul_samaneh@lilly.com

${ }^{1}$ Eli Lilly and Company, Lilly Corporate Center, Indianapolis, IN 46285, USA

Full list of author information is available at the end of the article
} 


\section{Background}

Severely insulin-resistant patients (daily insulin requirement $>200$ units or $>2$ units $/ \mathrm{kg}[1,2]$ ) with type 2 diabetes treated with high-dose insulin regimens are particularly burdened by longstanding inadequate glycemic control, multiple daily insulin injections, frequent glucose monitoring, obesity, highly prevalent comorbidities, and high healthcare costs, and often have compromised adherence [1-3]. Treatment using high doses of U-100 insulins intensifies barriers to use, as the number of daily injections, injection site discomfort, costs, and impaired adherence also increase [4-7].

Highly concentrated human regular U-500 insulin (U-500R; Humulin ${ }^{\circledR}$ R U-500, Eli Lilly and Company) is a treatment option that may alleviate some of these barriers. For a patient transitioning from a high-dose, high-volume regimen of U-100 insulin (100 units $/ \mathrm{mL}$ ) to one using U-500R, there is a reduction in the volume and the number of daily injections [3], in addition to the potential for decreased costs and improved adherence [4, 7]. While the use of U-500R has also been shown to improve patient satisfaction compared to high-dose U-100 insulins $[5,6]$ in previous retrospective analyses, this is the first study measuring patient perceptions in a controlled, randomized, clinical trial setting using U-500R.

In the clinical trial, 325 severely insulin-resistant patients with type 2 diabetes on high-dose U-100 insulin (>200 units of insulin/day) with or without oral antihyperglycemic agents were randomized to receive U-500R thrice daily (TID) or twice daily (BID), which was initiated and titrated over a 24-week period in place of U-100 insulins [3]. The objective of this analysis within the primary study was to compare patient-reported outcomes in the form of a diabetes treatment-specific questionnaire (Treatment Related Impact Measure-Diabetes [TRIM-D]), a quality of life questionnaire (EQ-5D-5L), and a pain scale, the Visual Analog Scale-Injection Site Pain (VASISP), before and after initiation of U-500R in TID and BID treatment groups. The hypothesis was that all instruments would improve with treatment on concentrated U-500R given the expected reduction in number of daily injections and insulin volume and anticipated glycated hemoglobin (HbA1c) improvement.

\section{Methods}

\section{Procedures}

The detailed trial design, including a description of the study population, has been previously reported but is discussed here briefly [3]. Baseline demographic and clinical characteristics of the TID and BID patients are provided in Table 1. For the overall study population, baseline body mass index was $41.9 \pm 7.5 \mathrm{~kg} / \mathrm{m}^{2}$, HbAlc was $8.7 \% \pm 1.0 \%$, median number of daily injections was 5 (range 2-10), and
Table 1 Baseline demographics and clinical characteristics of patients randomized to the TID and BID dosing algorithms ${ }^{a}$

\begin{tabular}{|c|c|c|c|}
\hline & $\begin{array}{l}\text { U500R TID } \\
(n=162)\end{array}$ & $\begin{array}{l}\text { U500R BID } \\
(n=163)\end{array}$ & $p$ value \\
\hline Male, n (\%) & $83(51.2)$ & $89(54.6)$ & .54 \\
\hline \multicolumn{3}{|l|}{ Race, n (\%) } & \multirow[t]{6}{*}{$.66^{b}$} \\
\hline White & $133(82.1)$ & $133(81.6)$ & \\
\hline Black & $21(13.0)$ & $19(11.7)$ & \\
\hline Asian & $2(1.2)$ & $4(2.5)$ & \\
\hline Native American & $3(1.9)$ & \multirow{2}{*}{$\begin{array}{l}1(0.6) \\
6(3.7)\end{array}$} & \\
\hline Other & $3(1.9)$ & & \\
\hline Ethnicity (Hispanic), n (\%) & $32(19.8)$ & $30(18.4)$ & .76 \\
\hline Age, years ${ }^{c}$ & $55.3 \pm 10.5$ & $55.5 \pm 9.0$ & .86 \\
\hline Weight, kg & $120.9 \pm 25.1$ & $122.9 \pm 26.2$ & .48 \\
\hline BMI, kg/m² & $41.8 \pm 7.6$ & $41.9 \pm 7.3$ & .95 \\
\hline Baseline $\mathrm{HbA}_{\mathrm{c}}$ & $8.7 \pm 1.1$ & $8.7 \pm 1.0$ & .87 \\
\hline Diabetes duration, years & $14.9 \pm 6.8$ & $15.5 \pm 8.0$ & .51 \\
\hline TDD, (U-100, final), units & $287.1 \pm 79.9$ & $287.8 \pm 81.2$ & .94 \\
\hline $\begin{array}{l}\text { Number of injections, median } \\
\text { [min, max }]\end{array}$ & $5[2,9]$ & $5[2,10]$ & .96 \\
\hline \multicolumn{4}{|c|}{ 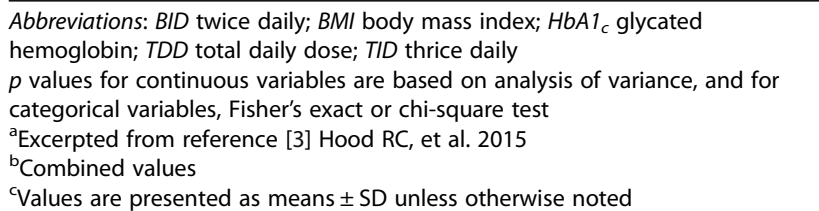 } \\
\hline
\end{tabular}

total daily dose (TDD) was $287.5 \pm 80.5$ units/day $(2.4 \pm 0.8$ units $/ \mathrm{kg} /$ day) [3]. Baseline insulin therapies included basal bolus (69.6\% [96.5\% analog insulins]), premixed insulin (12.3\%), basal only (6.2\%), and other (12.0\%) [3]. All patients were prior U-100 insulin users who were placed on a 4-week lead-in period, during which U-100 doses were verified and adjusted per investigators' judgment. Patients were then randomized to receive subcutaneous U-500R TID $(n=162)$ or BID $(n=163)$ [3]. The syringes provided for administration were 6-mm, 31-gauge U-100 insulin syringes (Becton, Dickinson and Company) and dosing was recommended 30 min before meals for both treatment groups. Patient-reported outcome measures, including the TRIM-D [8], EQ-5D-5L [9, 10], and VAS-ISP [11], were used to compare changes in diabetes treatment-related impact measures, quality of life, and injection site pain from baseline to endpoint between and within the BID and TID treatment groups. The TRIM-D and EQ-5D-5L assessments were performed at visit 1 (screening, -4 weeks), visit 3 (baseline/randomization, 0 weeks), and visit 16 (endpoint, 24 weeks) or early termination (if patients did not reach 24 weeks of study). The VAS-ISP was completed at visit 3 (baseline/randomization), visit 12 (12 weeks), and visit 16 (endpoint). Descriptive statistics by treatment and injection method were also provided as part of this analysis. The ethics review boards provided written approval of the study 
protocol and the informed consent form. The study was conducted in accordance with the International Conference on Harmonisation Guidelines for Good Clinical Practice and the Declaration of Helsinki and all patients provided written informed consent.

\section{Measures}

The TRIM-D is a validated, patient-reported outcome measure that assesses treatment-related impact on participants with type 1 or type 2 diabetes $[8,12$, 13]. The instrument consists of 28 items that are measured on a 5-point Likert scale, with higher scores indicating a better health state. TRIM-D items make up the following five domains: treatment burden (six items), daily life (five items), diabetes management (five items), compliance (four items), and psychological health (eight items). For example, items on the compliance domain depict how often a medication is missed, delayed, or postponed on a response scale ranging from never/almost never to almost always/always. Transformed scale scores range from 0 to 100, with higher scores indicating a better health state (less negative impact). The reliability and validity for TRIM-D has been previously assessed [12].

The EQ-5D-5L is a generic, well-validated, patientreported outcome measure consisting of the descriptive system and Visual Analog Scale (EQ-5D VAS) [9, 10]. The descriptive system captures 5 dimensions (mobility, self-care, usual activity, pain/discomfort, and anxiety/depression), and each dimension has 5 levels (no problems, slight problems, moderate problems, severe problems, and extreme problems). The respondents were asked to indicate their health status by checking item boxes on the questionnaire that fit the way they felt about their health on that day. The EQ-5D VAS measures the respondent's self-rated health on a $20-\mathrm{cm}$ vertical VAS numbered from 0 to 100, with 0 representing the worst health and 100 the best health imaginable. The EQ-5D$5 \mathrm{~L}$ has been validated in a diverse patient population in 6 countries and many different chronic disease states, including diabetes, for all dimensions and all levels [10]. Reliability and responsiveness remain to be assessed for the EQ-5D-5L [10].

The VAS-ISP assesses injection site pain over the past 24 h using a 100-mm horizontal VAS with anchors from "no pain" to "as severe as I can imagine" derived from Huskisson [11]. Early in the study, the VAS-ISP version of the questionnaire administered in this trial was modified from pain intensity 'now' to a corrected version of the VAS-ISP questionnaire with the time frame of the 'past 24 h'. Results from both instruments were analyzed and found to be comparable. The reliability and responsiveness of the VAS-ISP has not been assessed.

\section{Statistical analyses}

Baseline measurements for continuous variables were evaluated using analysis of variance. The EQ-5D-5L US Index and EQ-5D VAS values were calculated using the crosswalk method [10]. The TRIM-D, EQ-5D-5L, and VAS-ISP scores were compared between treatment groups at screening and baseline using analysis of covariance (ANCOVA). Change from baseline to endpoint scores were compared between treatment groups using the ANCOVA model with treatment as factor, baseline HbA1c, baseline TDD, investigator site, and baseline score as covariates. Comparisons of within-treatment group scores were conducted using mixed-effect model repeated measures (MMRM) with treatment, visit, interaction between treatment and visit, baseline HbA1c, TDD, investigator site, and baseline score as covariates using an unstructured covariance matrix.

The study population was categorized based on reduction of per-day insulin injections in the transition from U-100 to U-500 (0-2, 3-4, >4 per day). TRIM-D and EQ-5D-5L scores for subgroups were compared between treatment groups using an ANCOVA model. Based on the conventional definition of $80 \%$ compliance being clinically meaningful for adherence to diabetes medications, an arbitrary cutoff of TRIM-D compliance score $\geq 80$ (the lowest and highest possible raw scores are 28 and 140, and after transformation, the lowest and highest possible score is $0-100$ ) was used to compare the percentage achieving scores of $\geq 80$ versus $<80$ between the two treatment groups $[14,15]$. Logistic regression was used with treatment, baseline score, and baseline stratification variables (baseline HbA1c $\leq 8 \%$ or $>8 \%$, baseline TDD $\leq 300$ or $>300$ units) as independent variables. The dependent variable was patients achieving a TRIM-D score $\geq 80$.

The sample size calculation was based on the primary outcome: change in HbA1c from randomization to week 24 [3]. It was estimated that 260 completers would provide at least $80 \%$ probability to determine noninferiority of BID to TID, or vice versa, for the primary endpoint (non-inferiority margin $0.4 \%$ \%). Patientreported outcomes were exploratory. The $p$-values $<.05$ were considered statistically significant. All analyses were performed using SAS version 9.2 or higher (SAS Institute, Inc., Cary, $\mathrm{NC}$ ) and were based on the full analysis set.

\section{Results}

Baseline demographic and clinical characteristics of patients titrated to the TID and BID algorithms were well balanced (Table 1). The two treatment groups were comparable at baseline with no significant differences in these measured variables. 
Table 2 Comparisons of TID and BID dosing algorithms using TRIM-D patient-reported outcomes

\begin{tabular}{|c|c|c|c|c|}
\hline TRIM-D Domain & U-500R Treatment (n) & Mean Actual Value (SD) & $\begin{array}{l}\text { Change from Baseline (MMRM) } \\
\text { LSM }(95 \% \text { CI) })^{\text {a }}\end{array}$ & $\begin{array}{l}\text { LSM Difference between } \\
\text { Treatments }(95 \% \text { Cl) vs. U-500R TID } \\
\end{array}$ \\
\hline \multicolumn{5}{|l|}{ Overall } \\
\hline \multirow[t]{2}{*}{ Screening } & TID (161) & $60.28(13.61)$ & $-2.65(-4.77,-0.53)^{*}$ & $0.50(-2.57,3.56)$ \\
\hline & BID (159) & $60.77(14.27)$ & $-2.53(-4.67,-0.38)^{*}$ & \\
\hline \multirow[t]{2}{*}{ Baseline } & $\mathrm{TID}(161)$ & $61.35(14.59)$ & & $1.09(-2.05,4.22)$ \\
\hline & BID (161) & $62.44(14.00)$ & & \\
\hline \multirow[t]{2}{*}{ Endpoint } & TID (159) & $68.31(14.14)$ & $6.04(3.81,8.26)^{* *}$ & $3.52(0.93,6.11)^{*}$ \\
\hline & BID (153) & $72.44(12.57)$ & $10.06(7.82,12.30)^{* *}$ & \\
\hline \multicolumn{5}{|l|}{ Treatment burden } \\
\hline \multirow[t]{2}{*}{ Screening } & TID (160) & $60.37(18.40)$ & $-2.75(-6.12,0.63)$ & $-1.23(-5.57,3.11)$ \\
\hline & BID (159) & $59.15(20.91)$ & $-2.63(-6.01,0.75)$ & \\
\hline \multirow[t]{2}{*}{ Baseline } & TID (160) & $62.69(19.39)$ & - & $-2.48(-6.93,1.97)$ \\
\hline & BID (160) & $60.21(21.02)$ & & \\
\hline \multirow[t]{2}{*}{ Endpoint } & TID (158) & $68.91(19.31)$ & $6.23(2.70,9.75)^{*}$ & $5.03(0.99,9.06)^{*}$ \\
\hline & BID (153) & $72.97(19.84)$ & $12.24(8.71,15.77)^{* *}$ & \\
\hline \multicolumn{5}{|l|}{ Daily life } \\
\hline \multirow[t]{2}{*}{ Screening } & TID (161) & $63.72(17.38)$ & $-0.72(-3.77,2.32)$ & $-0.50(-4.52,3.52)$ \\
\hline & BID (158) & $63.22(19.10)$ & $-1.46(-4.53,1.62)$ & \\
\hline \multirow[t]{2}{*}{ Baseline } & TID (161) & $62.50(17.69)$ & - & $0.97(-2.95,4.89)$ \\
\hline & $\mathrm{BID}(161)$ & $63.47(18.07)$ & & \\
\hline \multirow[t]{2}{*}{ Endpoint } & TID (159) & $66.17(17.78)$ & $1.75(-1.44,4.93)$ & $4.01(0.41,7.62)^{*}$ \\
\hline & BID (153) & $70.63(17.57)$ & $6.58(3.37,9.79)^{* *}$ & \\
\hline \multicolumn{5}{|c|}{ Diabetes management } \\
\hline \multirow[t]{2}{*}{ Screening } & $\mathrm{TID}(161)$ & $40.18(19.53)$ & $-3.71(-7.07,-0.35)^{*}$ & $4.27(-0.15,8.69)$ \\
\hline & BID (158) & $44.45(20.62)$ & $0.13(-3.26,3.52)$ & \\
\hline \multirow[t]{2}{*}{ Baseline } & TID (161) & $43.15(20.83)$ & - & $0.91(-3.67,5.49)$ \\
\hline & BID (161) & 44.07 (20.95) & & \\
\hline \multirow[t]{2}{*}{ Endpoint } & TID (159) & $57.02(18.92)$ & $13.40(9.89,16.92)^{* *}$ & $0.52(-3.62,4.65)$ \\
\hline & BID (153) & $57.87(19.75)$ & $14.89(11.35,18.43)^{* *}$ & \\
\hline \multicolumn{5}{|l|}{ Compliance } \\
\hline \multirow[t]{2}{*}{ Screening } & TID (161) & $65.06(17.34)$ & $-3.04(-5.79,-0.29)^{*}$ & $1.24(-2.64,5.11)$ \\
\hline & BID (158) & $66.30(17.84)$ & $-2.58(-5.37,0.22)$ & \\
\hline \multirow[t]{2}{*}{ Baseline } & TID (161) & $67.43(17.09)$ & - & $2.02(-1.76,5.79)$ \\
\hline & $\mathrm{BID}(161)$ & $69.45(17.33)$ & & \\
\hline \multirow[t]{2}{*}{ Endpoint } & TID (159) & $73.00(16.87)$ & $5.31(2.43,8.19)^{* *}$ & $4.48(1.50,7.47)^{*}$ \\
\hline & BID (153) & $78.12(14.52)$ & $9.89(6.98,12.80)^{* *}$ & \\
\hline \multicolumn{5}{|c|}{ Psychological health } \\
\hline \multirow[t]{2}{*}{ Screening } & TID (161) & $68.09(19.17)$ & $-2.90(-5.67,-0.13)^{*}$ & $-0.14(-4.36,4.08)$ \\
\hline & BID (159) & $67.95(19.20)$ & $-5.00(-7.80,-2.20)^{* *}$ & \\
\hline \multirow[t]{2}{*}{ Baseline } & TID (161) & $68.02(19.07)$ & - & $3.49(-0.50,7.47)$ \\
\hline & BID (161) & $71.51(17.23)$ & & \\
\hline \multirow[t]{2}{*}{ Endpoint } & TID (159) & $73.90(19.86)$ & $4.57(1.66,7.47)^{*}$ & $3.22(-0.11,6.56)$ \\
\hline & BID (153) & $79.49(16.00)$ & $7.50(4.58,10.43)^{* *}$ & \\
\hline
\end{tabular}

Abbreviations: BID twice daily; CI confidence interval; LSM least-square mean; MMRM mixed model for repeated measures; SD standard deviation; TID thrice daily; TRIM-D Treatment Related Impact Measure-Diabetes; U-500R human regular U-500 insulin

${ }^{a} p$-values and $95 \% \mathrm{Cl}$ of difference of LSM of change from baseline were from the MMRM model

${ }^{b} p$-values and $95 \% \mathrm{Cl}$ of difference of LSM of change from baseline were from the ANCOVA model

${ }^{*} p<.05 ;{ }^{* *} p<.001$ 
TRIM-D

Patients within each treatment group had statistically significant improvement overall and within each TRIM$\mathrm{D}$ domain (treatment burden, daily life [BID only], diabetes management, compliance, and psychological health) from baseline to endpoint (Table 2). Individuals in the BID group achieved statistically significant improved scores overall, and in the treatment burden, daily life, and compliance domains when compared to those in the TID group at endpoint.

The median number of U-100 injections per day at baseline was five for both groups, with a range of 2 to 9

Table 3 Relationship between TRIM-D overall and domain scores and the number of reduced injections from baseline to endpoint

\begin{tabular}{|c|c|c|c|c|c|}
\hline TRIM-D Domain & $\begin{array}{l}\text { Reduced Number of } \\
\text { Injections }\end{array}$ & $\begin{array}{l}\text { U-500R Treatment } \\
\text { (n) }\end{array}$ & $\begin{array}{l}\text { Mean Value } \\
\text { (SD) }\end{array}$ & $\begin{array}{l}\text { Change from } \\
\text { Baseline }\end{array}$ & $\begin{array}{l}\text { LSM Change from Baseline } \\
\text { (SE) }\end{array}$ \\
\hline \multirow[t]{6}{*}{ Overall } & \multirow[t]{2}{*}{$0-2$} & TID (121) & $67.78(14.60)$ & $5.74(13.98)$ & $6.15(1.08)^{*}$ \\
\hline & & BID (58) & $72.73(12.56)$ & 7.95 (13.37) & $10.51(1.60)^{*}$ \\
\hline & \multirow[t]{2}{*}{$3-4$} & TID (36) & 70.54 (12.39) & 11.32 (15.78) & $8.48(2.02)^{*}$ \\
\hline & & BID (85) & $72.06(12.89)$ & $10.83(13.71)$ & $9.86(1.29)^{*}$ \\
\hline & \multirow[t]{2}{*}{$>4$} & $\mathrm{TID}(2)$ & $59.82(16.41)$ & $3.57(6.31)$ & $-1.22(8.31)$ \\
\hline & & BID (10) & $74.02(10.65)$ & $10.27(10.88)$ & $9.89(3.79)^{*}$ \\
\hline \multirow[t]{6}{*}{ Treatment burden } & \multirow[t]{2}{*}{$0-2$} & TID (120) & 68.65 (19.77) & $5.36(21.62)$ & $7.09(1.69)^{*}$ \\
\hline & & $\mathrm{BID}(58)$ & $70.62(21.93)$ & $9.55(25.43)$ & $10.84(2.47)^{*}$ \\
\hline & \multirow[t]{2}{*}{$3-4$} & TID (36) & $70.37(18.06)$ & $8.91(21.92)$ & $6.61(3.14)^{*}$ \\
\hline & & BID (85) & 74.59 (18.91) & $15.08(21.02)$ & $12.78(2.00)^{*}$ \\
\hline & \multirow[t]{2}{*}{$>4$} & $\mathrm{TID}(2)$ & $58.33(17.68)$ & $0.00(11.79)$ & $-3.42(12.90)$ \\
\hline & & BID (10) & $72.92(14.33)$ & 9.58 (19.35) & $10.17(5.89)$ \\
\hline \multirow[t]{6}{*}{ Daily life } & \multirow[t]{2}{*}{$0-2$} & TID (121) & $65.51(18.76)$ & $2.24(19.05)$ & $2.61(1.50)$ \\
\hline & & BID (58) & $72.52(17.34)$ & 7.61 (19.99) & $8.85(2.22)^{*}$ \\
\hline & \multirow[t]{2}{*}{$3-4$} & TID (36) & $68.89(14.40)$ & $9.17(17.42)$ & $6.75(2.81)^{*}$ \\
\hline & & BID (85) & $69.24(17.33)$ & 7.18 (19.02) & $6.68(1.79)^{*}$ \\
\hline & \multirow[t]{2}{*}{$>4$} & $\mathrm{TID}(2)$ & $57.50(3.54)$ & $-7.50(10.61)$ & $-8.59(11.54)$ \\
\hline & & BID (10) & $71.50(21.61)$ & $4.00(16.12)$ & $5.46(5.27)$ \\
\hline \multirow{6}{*}{$\begin{array}{l}\text { Diabetes } \\
\text { management }\end{array}$} & \multirow[t]{2}{*}{$0-2$} & TID (121) & $56.46(19.32)$ & $12.33(23.57)$ & $12.95(1.72)^{*}$ \\
\hline & & BID (58) & $57.74(20.00)$ & $9.63(24.48)$ & $14.09(2.55)^{*}$ \\
\hline & \multirow[t]{2}{*}{$3-4$} & TID (36) & $59.44(17.92)$ & $19.83(27.95)$ & $15.08(3.23)^{*}$ \\
\hline & & BID (85) & $58.18(20.15)$ & $15.29(25.55)$ & $13.87(2.06)^{*}$ \\
\hline & \multirow[t]{2}{*}{$>4$} & TID (2) & $47.50(10.61)$ & 12.50 (17.68) & $5.38(13.29)$ \\
\hline & & $\mathrm{BID}(10)$ & $56.00(16.30)$ & $15.00(16.83)$ & $12.38(6.06)^{*}$ \\
\hline \multirow[t]{6}{*}{ Compliance } & \multirow[t]{2}{*}{$0-2$} & TID (121) & $72.47(17.61)$ & $4.17(15.47)$ & $4.27(1.24)^{*}$ \\
\hline & & BID (58) & $77.51(15.30)$ & $8.76(14.30)$ & $9.77(1.84)^{*}$ \\
\hline & \multirow[t]{2}{*}{$3-4$} & TID (36) & $75.00(14.56)$ & $9.72(22.43)$ & $7.34(2.33)^{*}$ \\
\hline & & BID (85) & $78.09(14.26)$ & $9.12(14.96)$ & $9.16(1.48)^{*}$ \\
\hline & \multirow[t]{2}{*}{$>4$} & TID (2) & $68.75(8.84)$ & $3.13(13.26)$ & $0.13(9.58)$ \\
\hline & & BID (10) & $81.88(12.66)$ & $7.50(13.44)$ & $9.27(4.37)^{*}$ \\
\hline \multirow[t]{6}{*}{ Psychological health } & \multirow[t]{2}{*}{$0-2$} & TID (121) & $73.30(20.56)$ & $4.76(17.85)$ & $4.45(1.38)^{*}$ \\
\hline & & BID (58) & $81.51(15.17)$ & $5.60(13.69)$ & $9.39(2.06)^{*}$ \\
\hline & \multirow[t]{2}{*}{$3-4$} & TID (36) & 76.39 (17.12) & $9.98(15.79)$ & $7.53(2.59)^{*}$ \\
\hline & & BID (85) & $77.61(16.86)$ & $8.01(18.10)$ & $7.28(1.65)^{*}$ \\
\hline & \multirow[t]{2}{*}{$>4$} & $\mathrm{TID}(2)$ & $65.63(30.94)$ & $7.81(2.21)$ & $0.78(10.68)$ \\
\hline & & BID (10) & $83.75(11.39)$ & $13.13(13.24)$ & $11.32(4.86)^{*}$ \\
\hline
\end{tabular}

Abbreviations: BID twice daily; LSM least-square mean; SD standard deviation; SE standard error; TID thrice daily; TRIM-D Treatment Related Impact MeasureDiabetes; U-500R human regular U-500 insulin 
for TID and 2 to 10 for BID (Table 1) [3]. Patients were grouped by number of injections reduced from baseline into three categories $(0-2,3-4$, and $>4)$, and these subgroups were analyzed separately for TRIM-D overall and specific domains at endpoint (Table 3). Individuals in the U-500R BID group reported significant improvements in overall score and each domain when 0-2 and 3-4 injections were reduced from baseline. The individuals in the TID group reported significant improvements in overall and in each domain when $0-2$ and 3-4 injections were reduced from baseline $(p<.05)$ except the daily life domain when $0-2$ injections were reduced from baseline. Significant differences may not have been seen in the $>4$ injections reduced category because of the small sample size (two in the TID group and ten in the BID group).

The compliance domain scores in the BID treatment group were significantly higher compared to the TID treatment group ( $p=.03$ in favor of BID vs. TID). The proportion of patients achieving a TRIM-D compliance score $\geq 80$ was analyzed by subordinate analysis using logistic regression and $36 \%(58 / 159)$ of patients in the TID treatment group vs. $49 \%(75 / 153)$ in the BID group had a TRIM-D compliance score of $\geq 80$ (odds ratio $=1.70 ; 95 \%$ confidence interval: $1.05-2.75 ; p=.03$ ) (Table 4).

\section{EQ-5D-5L}

EQ-5D-5L index scores showed no statistically significant differences between the TID and BID groups at screening, baseline/randomization, and endpoint (Table 5). Visit comparisons of total score for the overall population and TID and BID groups were conducted separately. No significant visit differences were found in scores between screening and baseline or between baseline and endpoint.

Although the number of injections in the TID and BID cohorts declined during the transition period of the study [3], neither the treatment (TID or BID) nor the number of reduced injections (i.e., $0-2,3-4$, or $>4$ ) had significant effect on the EQ-5D-5L index scores.

Summaries of responses which best described the respondent's health on the five EQ-5D-5L domains (mobility, self-care, usual activities, pain/discomfort, anxiety/ depression) showed no statistically significant difference between treatment groups at screening, baseline, or endpoint.
Quantitative EQ-5D VAS scores for overall health at screening, baseline, and endpoint in TID respondents were 70.0, 70.4, and 68.0, respectively (TID endpoint least-square means $p<.05$ compared to baseline); whereas, scores in BID respondents were not significantly different at 68.9, 70.8, and 70.0. Comparisons between TID and BID treatment groups were not significantly different.

\section{VAS-ISP}

VAS-ISP demonstrated a significant improvement in injection site pain from baseline to endpoint for TID and BID treatment groups (least square means change from baseline at visit $12,-7.36$ TID; -5.85 BID; and at visit 16, -5.60 TID; -6.47 BID; $p<.05$; Fig. 1). No significant difference of score reduction between BID and TID groups was evident.

\section{Discussion}

This is the first analysis of prospective and comprehensive patient-reported outcomes from a randomized, clinical trial of severely insulin-resistant patients with type 2 diabetes who were switched from high-dose U-100 insulin regimens to U-500R as insulin monotherapy. Consistent with the initial study hypothesis, transitioning from high-dose, high-volume U-100 insulin requiring multiple daily injections and implementing TID or BID U-500R dosing algorithms, most TRIM-D domain scores in patients demonstrated clinically relevant and significant improvements from baseline to endpoint. By endpoint, respondents in the BID group had experienced greater perceived improvements in TRIM-D over time when compared to the TID group. Respondents also reported improved compliance from baseline for both groups, and a higher proportion of BID group patients achieved a TRIM-D compliance score $\geq 80$.

As first reported by Hood et al. [3], the primary study outcome, change in HbA1c between TID and BID, was clinically equivalent between the two study groups (-1.12 \% TID;-1.22 \% BID; difference,-0.10\%; $95 \%$ confidence interval:-0.33 to $0.12 \%$; noninferiority margin, $0.4 \%)$. Despite an increase in TDD and significant reduction in HbA1c [3], both groups reported an improvement in compliance scores. This could be explained by better adherence with simplified insulin regimens wherein up to 10 injections daily of U-100

Table 4 Subanalysis of individuals with TRIM-D compliance score $\geq 80$ at endpoint ${ }^{\mathrm{a}}$

\begin{tabular}{|c|c|c|c|c|c|c|}
\hline & $\begin{array}{l}\text { U-500R TID } \\
(n=159) \\
\mathrm{n}(\%)\end{array}$ & $\begin{array}{l}\text { U-500R BID } \\
(n=153) \\
n(\%)\end{array}$ & $\begin{array}{l}\text { Total } \\
(N=312) \\
n(\%)\end{array}$ & $\begin{array}{l}\text { Odds Ratio } \\
\text { U-500R } \\
\text { BID/TID }\end{array}$ & $\begin{array}{l}95 \% \mathrm{Cl} \text { of } \\
\text { Odds Ratio }\end{array}$ & $p$-value \\
\hline Number of patients with TRIM-D compliance score $\geq 80$ & $58(36.5)$ & $75(49.0)$ & $133(42.6)$ & 1.70 & $1.05,2.75$ & .03 \\
\hline
\end{tabular}

Abbreviations: BID twice daily; $C$ confidence interval; $n$ number of patients in a specified group; $N$ total number of patients; TID thrice daily; TRIM-D Treatment Related Impact Measure-Diabetes; U-500R human regular U-500 insulin

${ }^{\mathrm{a}} \mathrm{Cl}$ and $p$-values were from a logistic regression model with fixed effects for treatment, baseline score and baseline stratification variables (Baseline $\mathrm{A} 1 \mathrm{C}(\leq 8 \%$ or $>8 \%$ ), Baseline TDD ( $\leq 300$ or $>300$ ), and pooled investigator). $p$-value from this analysis was based on a null hypothesis that the odds ratio is one 
Table 5 EQ-5D-5L index score comparing 2 U-500R dosing algorithms in individuals with severely insulin-resistant type 2 diabetes

\begin{tabular}{|c|c|c|c|c|}
\hline $\begin{array}{l}\text { EQ-5D-5L } \\
\text { US Index- } \\
\text { Visit }\end{array}$ & $\begin{array}{l}\text { U-500R } \\
\text { Treatment } \\
\text { (n) }\end{array}$ & $\begin{array}{l}\text { LSM } \\
\text { (SE) }\end{array}$ & $\begin{array}{l}p \text {-value Visit } \\
\text { Comparison } \\
\left(_{\text {Change from Baseline })^{a}}\right.\end{array}$ & $\begin{array}{l}\text { LSM } \\
\text { Difference } \\
\text { (95\% CI) vs } \\
\text { U-500R TID }\end{array}$ \\
\hline \multirow[t]{2}{*}{ Screening } & TID (161) & $\begin{array}{l}0.77 \\
(0.01)\end{array}$ & 0.97 & \multirow[t]{2}{*}{$\begin{array}{l}0.01(-0.02, \\
0.04)\end{array}$} \\
\hline & BID (158) & $\begin{array}{l}0.78 \\
(0.01)\end{array}$ & 0.35 & \\
\hline \multirow[t]{2}{*}{ Baseline } & TID (162) & & - & \multirow{2}{*}{$\begin{array}{l}0.00(-0.03, \\
0.03)\end{array}$} \\
\hline & BID (161) & & - & \\
\hline \multirow[t]{2}{*}{ Endpoint } & TID (159) & $\begin{array}{l}-0.02 \\
(0.01)\end{array}$ & 0.30 & \multirow[t]{2}{*}{$\begin{array}{l}0.01(-0.02, \\
0.03)\end{array}$} \\
\hline & BID (152) & $\begin{array}{l}-0.01 \\
(0.01)\end{array}$ & 0.80 & \\
\hline
\end{tabular}

Abbreviations: BID twice daily; CI confidence interval; LSM least-square mean; SE standard error; TID thrice daily; U-500R human regular U-500 insulin ${ }^{a} p$-values and $95 \% \mathrm{Cl}$ of difference of LSM of change from baseline were from the MMRM model

were prescribed before randomization (often with more than one insulin), compared to a monotherapy regimen of two or three injections of U-500R postrandomization.

Although EQ-5D VAS comparisons between the TID and BID groups were not significantly different, individuals in the TID group responded with statistically lower health scores from baseline at endpoint. Because the EQ-5D-5L is not diabetes specific, the assessment may not have been sensitive enough to distinguish between treatment groups.

Injection site pain was significantly reduced in both treatment groups, which might be attributed to the reduced daily injection volume $(-2.2 \mathrm{~mL}$ for TID and BID) and reduced number of daily injections ( -2 TID, -3 BID) $[3,16]$. This finding supports prior reports of reduced injection site discomfort with use of concentrated U-500R [5, 17-19].

Limitations of this study included the open-label design and lack of direct measures of compliance. Patient perceptions of use while on vial and syringe versus pen regimens prior to randomization to U-500R were not evaluated separately, which could also have impacted patient perception of the new insulin regimen (vial and syringe).

Since this analysis takes into account the patient perspective, an additional factor not analyzed here that could affect the patient perception is the affordability of insulin. In recent years, this has become a significant issue, especially for those patients requiring high doses of insulin [20] to achieve glycemic control. For the majority of patients in this trial using basal + bolus analog insulin regimens $(67 \%$ of patients) prior to randomization to U-500R, one would expect that the switch to U-500R would lead to a reduction in daily insulin costs. This decrease might be expected to occur after accounting for an increase in TDD from baseline to endpoint regimens after 24 weeks as part of a titration-to-target intensification. While this reduction in real-world drug costs with transition to U-500R has

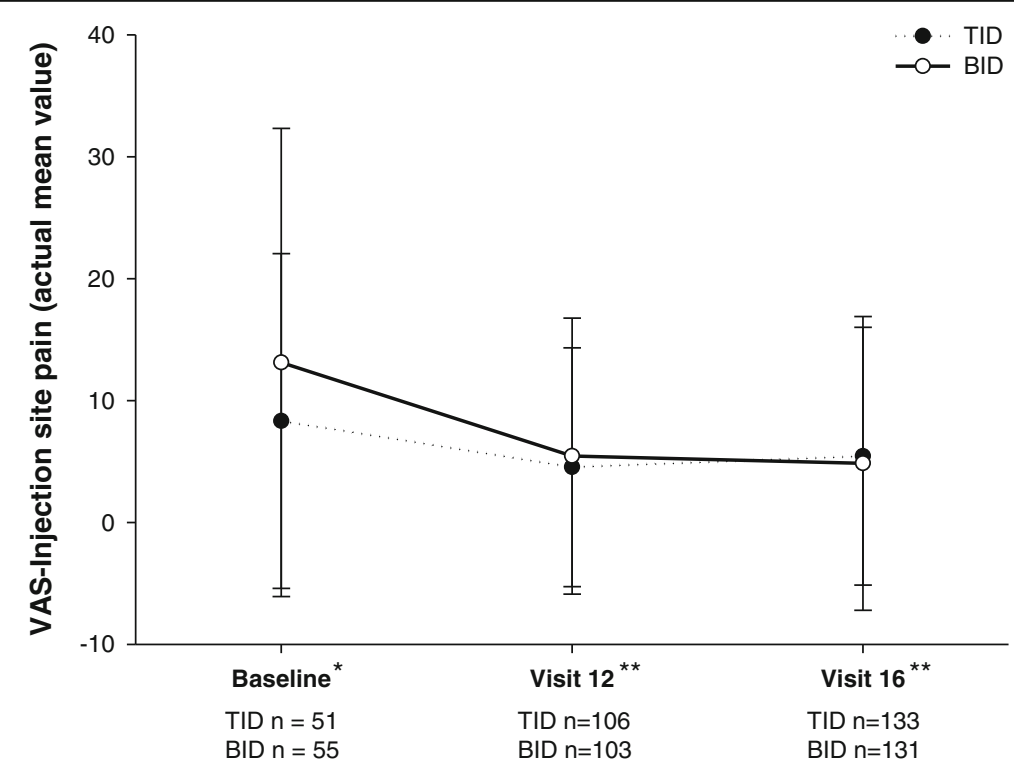

Fig. 1 Visual Analog Scale - Injection Site Pain evaluation from baseline to endpoint. Abbreviations: BID = twice daily; SD = standard deviation; TID = thrice daily; VAS = visual analog scale. *Actual mean values of patients on U100 insulins \pm SD are from corrected CRF data. ${ }^{*} p$-values are $<0.05$ for visit 12 and visit 16 when least square mean change from baseline are calculated (-7.36 TID, -5.85 BID visit 12 and -5.60 TID, -6.47 BID visit 16) 
previously been reported as compared to propensitymatched patients remaining on high-dose conventional U-100 insulins [4, 7], further detailed economic analyses on this topic would be of value to patients, payers, and providers alike.

\section{Conclusion}

Our study findings indicate that initiation and titration of U-500R leads to improved patient perception, improved impact of diabetes treatment on functioning and wellbeing, and less injection site discomfort following use of high-dose, high-volume U-100 insulins in severely insulinresistant patients with type 2 diabetes. While both regimens improved patient reported treatment-related diabetes measures, the twice-daily regimen showed more of an improvement in certain patient reported domains when compared to the thrice-daily regimen. Its impact on compliance, specifically, should therefore be considered when choosing an appropriate U-500 regimen in a clinical practice setting. These results are complementary to the primary clinical trial findings, which showed significantly improved glycemic control with low incidence and rates of severe hypoglycemia with fewer daily injections [3]. These results can be further complemented by appropriately designed, prospective, real-world analyses accounting for other patient and economic factors that were not studied here.

\section{Abbreviations}

ANCOVA: analysis of covariance; BID: twice daily; EQ-5D-5L: quality of life questionnaire; HbA1c: glycated hemoglobin; MMRM: mixed-effect model repeated measures; TDD: total daily dose; TID: thrice daily; TRIM-D: Treatment Related Impact Measure-Diabetes; U-500R: human regular U-500 insulin: VAS: visual analog scale; VAS-ISP: Visual Analog Scale-Injection Site Pain

\section{Acknowledgments}

The writing and editing of the manuscript were funded by Eli Lilly and Company (Indianapolis, Indiana), the manufacturers of U-100 insulins and U-500R. The authors thank Emily Cullinan and Teri Tucker, of inVentiv Health Clinical, for their writing and editorial support.

\section{Funding}

The research of the manuscript was funded by Eli Lilly and Company (Indianapolis, Indiana).

\section{Availability of data and material}

Lilly provides access to the individual patient data from studies on approved medicines and indications as defined by the sponsor specific information on clinicalstudydatarequest.com. Researchers need to have an approved research proposal submitted through clinicalstudydatarequest.com. Access to the data will be provided in a secure data sharing environment after signing a data sharing agreement.

\section{Authors' contributions}

$\mathrm{JS}$ and $\mathrm{RH}$ conceived and designed the study. JS and RH collected the data. $J S, S K, A D, R D$, and RD analyzed and interpreted the data. All authors were involved in the drafting, review, and approval of the report and the decision to submit for publication.

\section{Competing interests}

S.K., R.D., A.M.D., and J.S. are employed by Eli Lilly and Company and/or one of its subsidiaries and are minor stockholders in Eli Lilly and Company. R.C.H. has served as a consultant for and received research funding from Eli Lilly and Company and Novo Nordisk, serves on the advisory boards for Eli Lilly and Company and Takeda, and is on the speakers' bureaus of AstraZeneca, Boehringer Ingelheim, Eli Lilly and Company, GlaxoSmithKline, Janssen, Novo Nordisk, and Takeda. The authors have no other conflicts of interest with regard to the content of this article.

\section{Consent for publication}

Not applicable

\section{Ethics approval and consent to participate}

The ethics review boards of Chesapeake Research Review, Creighton University Medical Center, Mercy Medical Center, Mercy Medical Research Institute, Schulman and Associates IRB, Thomas Jefferson University, University of Hawaii Committee on Human Studies, University of Missouri, University of Oklahoma IRB, University of Texas Southwestern at Dallas Children's Medical Center, UNC Diabetes Care Center, Vanderbilt University School of Medicine, and Western Institutional Review Board provided written approval of the study protocol and the informed consent forms. The study was conducted in accordance with the International Conference on Harmonisation Guidelines for Good Clinical Practice and the Declaration of Helsinki and all patients provided written informed consent.

\section{Author details}

${ }^{1}$ Eli Lilly and Company, Lilly Corporate Center, Indianapolis, IN 46285, USA. ${ }^{2}$ Endocrine Clinic of Southeast Texas, 3030 North Street, Suite 560, Beaumont, TX 77702, USA.

Received: 6 May 2016 Accepted: 17 September 2016 Published online: 30 September 2016

\section{References}

1. Lane WS, Cochran EK, Jackson JA, Scism-Bacon JL, Corey IB, Hirsch IB, et al. Highdose insulin therapy: is it time for U-500 insulin? Endocr Pract. 2009;15:71-9.

2. Ovalle F. Clinical approach to the patient with diabetes mellitus and very high insulin requirements. Diabetes Res Clin Pract. 2010;90:231-42.

3. Hood RC, Arakaki RF, Wysham C, Li YG, Settles JA, Jackson JA. Two treatment approaches for human regular $\mathrm{U}-500$ insulin in patients with type 2 diabetes not achieving adequate glycemic control on high-dose U-100 insulin therapy with or without oral agents: a randomized, titration-to-target clinical trial. Endocr Pract. 2015;21:782-93.

4. Eby EL, Zagar AJ, Wang P, Curtis BH, Xie J, Haldane DC, et al. Healthcare costs and adherence associated with human regular $\mathrm{U}-500$ versus highdose U-100 insulin in patients with diabetes. Endocr Pract. 2014;20:663-70

5. Dailey AM, Williams S, Taneja D, Tannock LR. Clinical efficacy and patient satisfaction with U-500 insulin use. Diabetes Res Clin Pract. 2010;88:259-64.

6. Bulchandani DG, Konrady T, Hamburg MS. Clinical efficacy and patient satisfaction with U-500 insulin pump therapy in patients with type 2 diabetes. Endocr Pract. 2007;13:721-5.

7. Eby EL, Wang P, Curtis BH, Xie J, Haldane DC, Idris I, et al. Cost, healthcare resource utilization, and adherence of individuals with diabetes using U-500 or U-100 insulin: a retrospective database analysis. J Med Econ. 2013;16:529-38.

8. Savre I. TRIM-D treatment related impact measure-diabetes. Lyon: Mapi Research Trust; 2013

9. Herdman M, Gudex C, Lloyd A, Janssen M, Kind P, Parkin D, et al. Development and preliminary testing of the new five-level version of EQ-5D (EQ-5D-5L). Qual Life Res. 2011;20:1727-36.

10. Oemar M, Janssen B. EQ-5D-5L User Guide: Basic Information on How to Use the EQ-5D-5L Instrument. Rotterdam: EuroQol Group; 2015.

11. Huskisson EC. Measurement of pain. Lancet. 1974;2:1127-31.

12. Brod M, Hammer M, Christensen T, Lessard S, Bushnell DM. Understanding and assessing the impact of treatment in diabetes: the Treatment-Related Impact Measures for Diabetes and Devices (TRIM-Diabetes and TRIMDiabetes Device). Health Qual Life Outcomes. 2009;7:83.

13. Brod M, Christensen T, Hammer M, Busk AK, Bushnell DM. Examining the ability to detect change using the TRIM-Diabetes and TRIM-Diabetes Device measures. Qual Life Res. 2011;20:1513-8.

14. Asche C, LaFleur J, Conner C. A review of diabetes treatment adherence and the association with clinical and economic outcomes. Clin Ther. 2011;33:74-109.

15. Peterson AM, Nau DP, Cramer JA, Benner J, Gwardry-Sridhar F, Nichol M. A checklist for medication compliance and persistence studies using retrospective databases. Value Health. 2007;10:3-12. 
16. Heise T, Nosek L, Dellweg S, Zijlstra E, Præstmark KA, Kildegaard J, et al. Impact of injection speed and volume on perceived pain during subcutaneous injections into the abdomen and thigh: a single-centre, randomized controlled trial. Diabetes Obes Metab. 2014;16:971-6.

17. Knee TS, Seidensticker DF, Walton JL, Solberg LM, Lasseter DH. A novel use of $\mathrm{U}-500$ insulin for continuous subcutaneous insulin infusion in patients with insulin resistance: a case series. Endocr Pract. 2003;9:181-6.

18. Garg R, Johnston V, McNally PG, Davies MJ, Lawrence IG. U-500 insulin: why, when and how to use in clinical practice. Diabetes Metab Res Rev. 2007;23:265-8.

19. Lane WS. Use of U-500 regular insulin by continuous subcutaneous insulin infusion in patients with type 2 diabetes and severe insulin resistance. Endocr Pract. 2006;12:251-6.

20. Tylee T, Hirsch IB. Costs associated with using different insulin preparations. JAMA. 2015;314:665-6.

Submit your next manuscript to BioMed Central and we will help you at every step:

- We accept pre-submission inquiries

- Our selector tool helps you to find the most relevant journal

- We provide round the clock customer support

- Convenient online submission

- Thorough peer review

- Inclusion in PubMed and all major indexing services

- Maximum visibility for your research

Submit your manuscript at www.biomedcentral.com/submit
Biomed Central 